\title{
THERMAL STRESS ANALYSIS IN THE COATED UPPER CANINE
}

\author{
Mümin Küçük \\ Ege University Ege Training Higher School , Bornova, İzmir, Turkey
}

\begin{abstract}
The aim of this study is to investigate the thermal stresses caused by temperature change on the upper canine coated by various dental materials. In this study, first of all the modeling of tooth has been done by using a specific computer program Ansys 5.3 that is capable of both finite element modeling and stress-strain analysis. Secondly, thermal stresses arising from the temperature difference between the tooth temperature and the temperatures of the food and drinks taken to mouth have been examined. It has been demonstrated that the lowest thermal stresses occur in metal crowns, while the highest thermal stresses occur in metalceramic crowns. It has been shown that metal-ceramic crowns are more prone in terms of heat compared to metal crowns and that these crowns may deteriorate in time and may even become unusable.
\end{abstract}

\section{INTRODUCTION}

It is no doubt that teeth are very important in terms of human health. Nevertheless, teeth also get deformed in parallel to the aging of the body. In this case, the tooth is restored in order to continue its functions. First of all, it must be guaranteed that the materials used in the tooth are suitable both biologically and chemically. Besides this, the main object is to achieve a crown that will be used without corrosion and failure, as long as possible; since it is a highly expensive procedure to replace these crowns. In addition to these, factors such as strength, aesthetics, ease of manufacture and cost are reasons for preference.

A complete evaluation of a new or improved restorative material may require the combined efforts of the dentist, materials scientist, and biologist. As a result, orderly study of the properties of restorative materials has developed into a special branch or bioengineering. The application of bioengineering principles to restorative materials will expend in the years ahead.

In this study, the thermal stresses occurring due to the intake of cold or hot food and beverages, in the canine teeth crowned with various crown materials are investigated. Firstly, the modelling of tooth has been done by using a specific computer program Ansys 5.3 which is capable of both finite element modelling and stress-strain analysis. The temperature of cold food and drinks that can be taken to mouth can be accepted as minimum $0{ }^{\circ} \mathrm{C}$ while the highest temperature for hot food and drinks can be $60^{\circ} \mathrm{C}$ [1]. In this study, the initial temperatures of hot drinks have been selected to be $60^{\circ} \mathrm{C}$. It is assumed that these temperatures have reached to mouth temperature $\left(36.5^{\circ} \mathrm{C}\right)$ in one second [2]. Since in porcelain crowns heating of the crown are more dangerous than its cooling [3] this study has been carried out for hot food and drinks taken to mouth. In the studies carried out under these circumstances, the simulated model was demonstrated to be in good agreement with theoretical and experimental studies as mentioned above. The results of this study will be used comfortably in the following studies concerning transient thermal stress analysis within the tooth. Secondly, thermal stresses arising from the temperature difference between the tooth temperature and the temperatures of the food and drinks taken to mouth have been examined. The hot and cold drinks in mouth cause a temperature gradient in tooth; this gradient results in thermal stresses because of the different physical properties of different materials in tooth. Two main crown materials are used for the crown part of the tooth. These are Metal Crowns and Metal-Ceramic Crowns. Taking into 
consideration all of the facts, transient thermal stress distribution occurring in the tooth and the crown has been investigated

It is known that Metal-Ceramic crowns are prone to failure. Failure, due to the deepening of the existing surface cracks at the surface or at the inner parts, may occur in the porcelain used in Metal-Ceramic crowns due to manufacturing [4]. In this study, it is shown that the thermal stresses occurring in these crowns are greater than those occurring in metal crowns.

\section{MATERIALS AND METHOD}

The aim of this study is to find the thermal stresses in a three-dimensional model of the maxillary right canine. The Maxillary Right Canine is the third tooth from the median line in the maxilla. The Palmer Notation is the simplest and the most universally used code for dental records. Only eight different names of teeth need to be remembered (Fig. 1) The dimensions of the tooth are given in Table 1. The geometry of the tooth has been taken from Wheeler's An Atlas of Tooth Form [5] as shown in Fig. 2

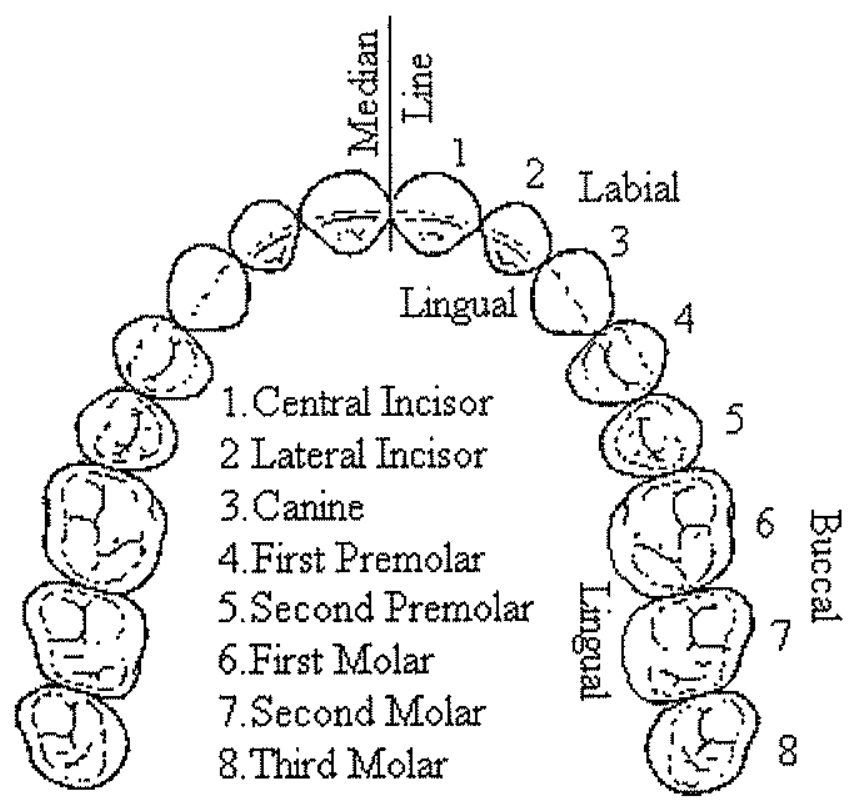

Figure 1. Name and numbers of teeth and their relationship to median line of the dental arches.

Table 1 Dimensions of the Tooth (mm)

\begin{tabular}{|l|c|}
\hline Cervico-Incisal Length of Crown & 10.0 \\
\hline Length of Root & 17.0 \\
\hline Mesio-Distal Diameter of Crown & 7.5 \\
\hline Mesio-Distal Diameter at Cervix & 5.5 \\
\hline Labio-(or Bucco) Lingual Diameter & 8.0 \\
\hline Labio-Lingual Diameter at Cervix & 7.0 \\
\hline Curvature of Cervical Line-Mesial & 2.5 \\
\hline Curvature of Cervical Line-Distal & 1.5 \\
\hline
\end{tabular}




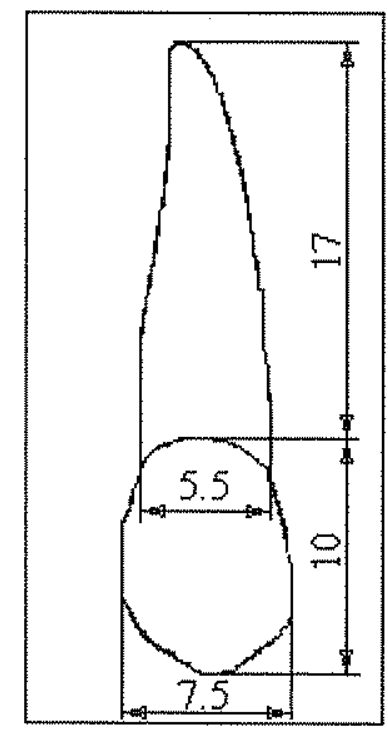

Labiat

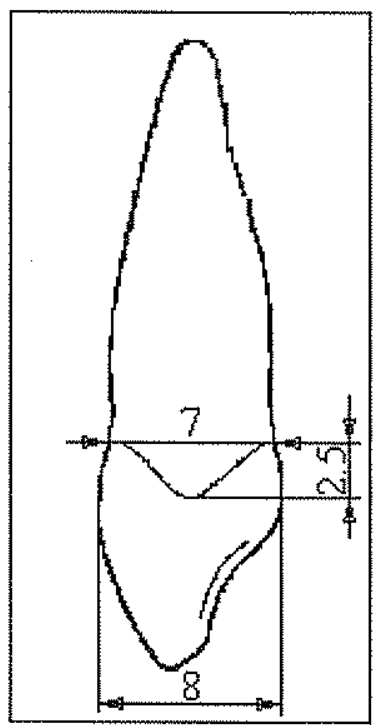

Mesial

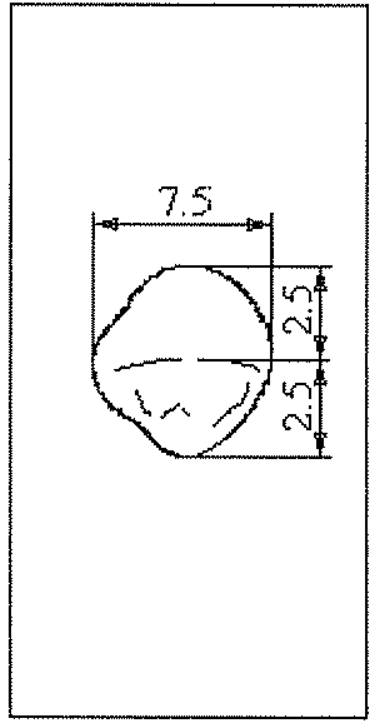

Incisal

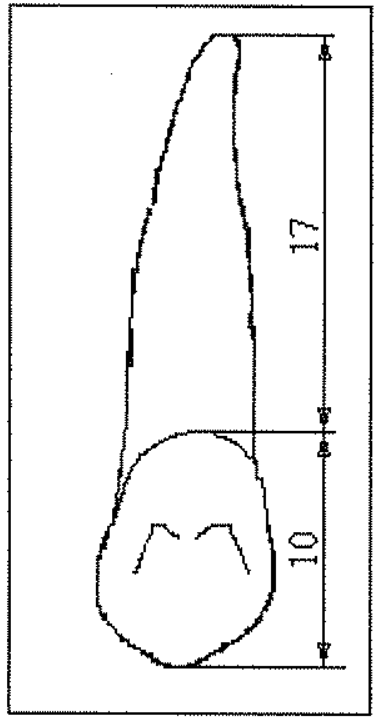

Lingual

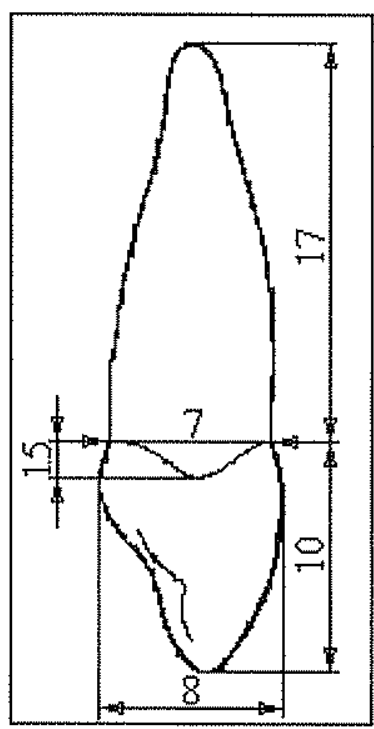

Distal

Figure 2. The geometry of the maxillary right canine.

The modelling of tooth has been done by using a specific computer program Ansys 5.3 which is capable of both finite element modelling and stress-strain analysis as shown in Figure .3. The elements of the tooth are shown in Figure 4 . The total number of elements is 4101 with 4255 nodes. 


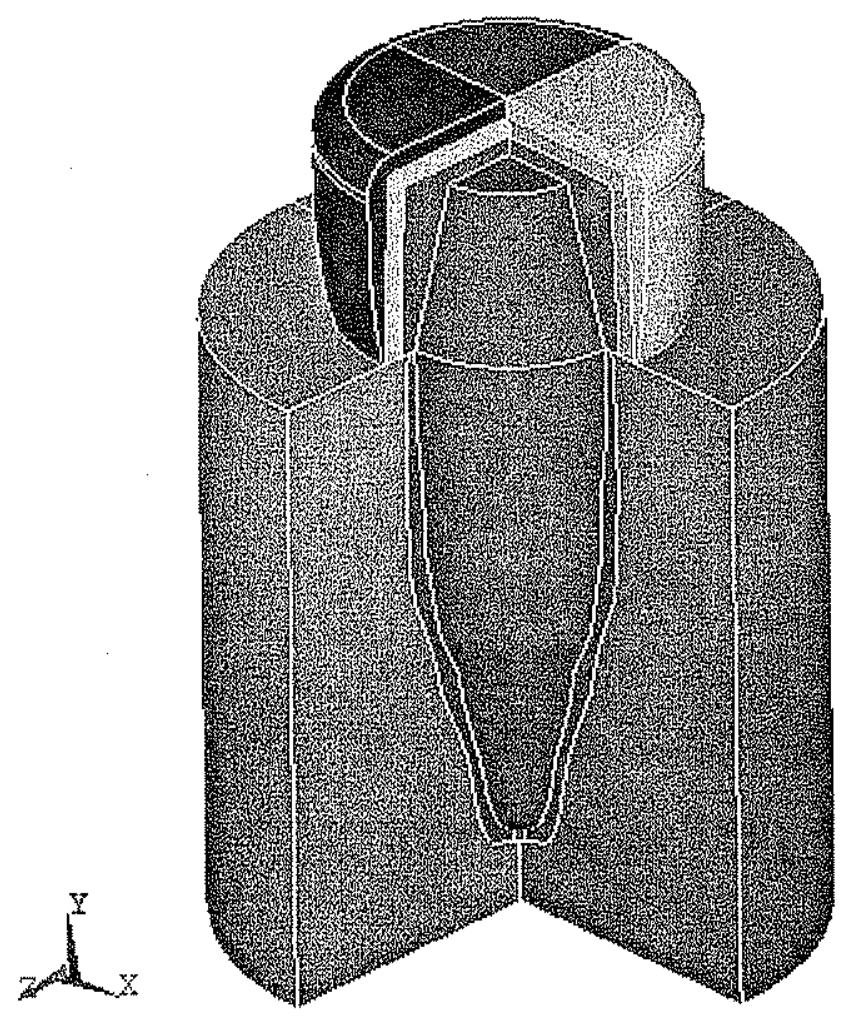

Figure 3 Modelling of tooth by using Ansys

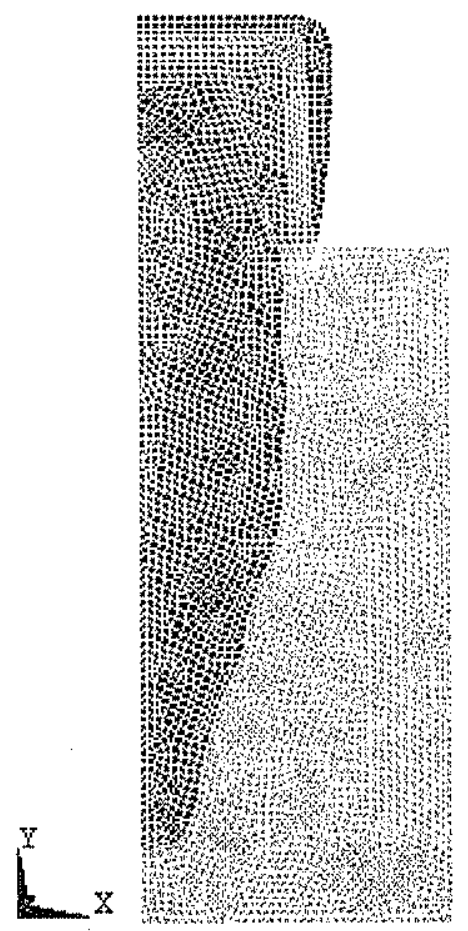

Figure 4 Elements of tooth as obtained by Ansys 
As known, a tooth is made up of three sections. These are Enamel, Dentine and Pulp Tissue. The physical properties of these sections are given Table 2. The enamel and dentine parts of the tooth has been cut and coated with various crown materials as seen in Fig. 5. It is assumed that the highest temperature of food and drinks that can be taken to mouth is $60^{\circ} \mathrm{C}$. In other words, the initial temperature of drinks have been selected to be $60{ }^{\circ} \mathrm{C}$. It is assumed that this temperature has reached to mouth temperature $\left(36.5{ }^{\circ} \mathrm{C}\right)$ in one second. The temperature distribution occurring in the tooth and the crown within these circumstances have been examined along the $x-x$ and $y-y$ lines as shown in Fig. 5.

Table 2 Physical Properties of Tooth

\begin{tabular}{|l|c|c|c|}
\hline \multicolumn{1}{|c|}{ Material } & $\begin{array}{c}\text { Modulus of Elasticity } \\
(\mathrm{MPa})\end{array}$ & Poisson's ratio & $\begin{array}{l}\text { Density } \\
(\mathrm{kg} / \mathrm{mm} 3) \mathrm{x} 10 \mathrm{E} 6\end{array}$ \\
\hline Enamel & 48000 & 0.33 & 2.97 \\
\hline Dentine & 18600 & 0.31 & 2.14 \\
\hline Periodontal ligament & 68.9 & 0.45 & 1 \\
\hline Pulp tissue & 2.3 & 0.45 & - \\
\hline Alveolar Bone & 19620 & 0.30 & 1.3 \\
\hline
\end{tabular}
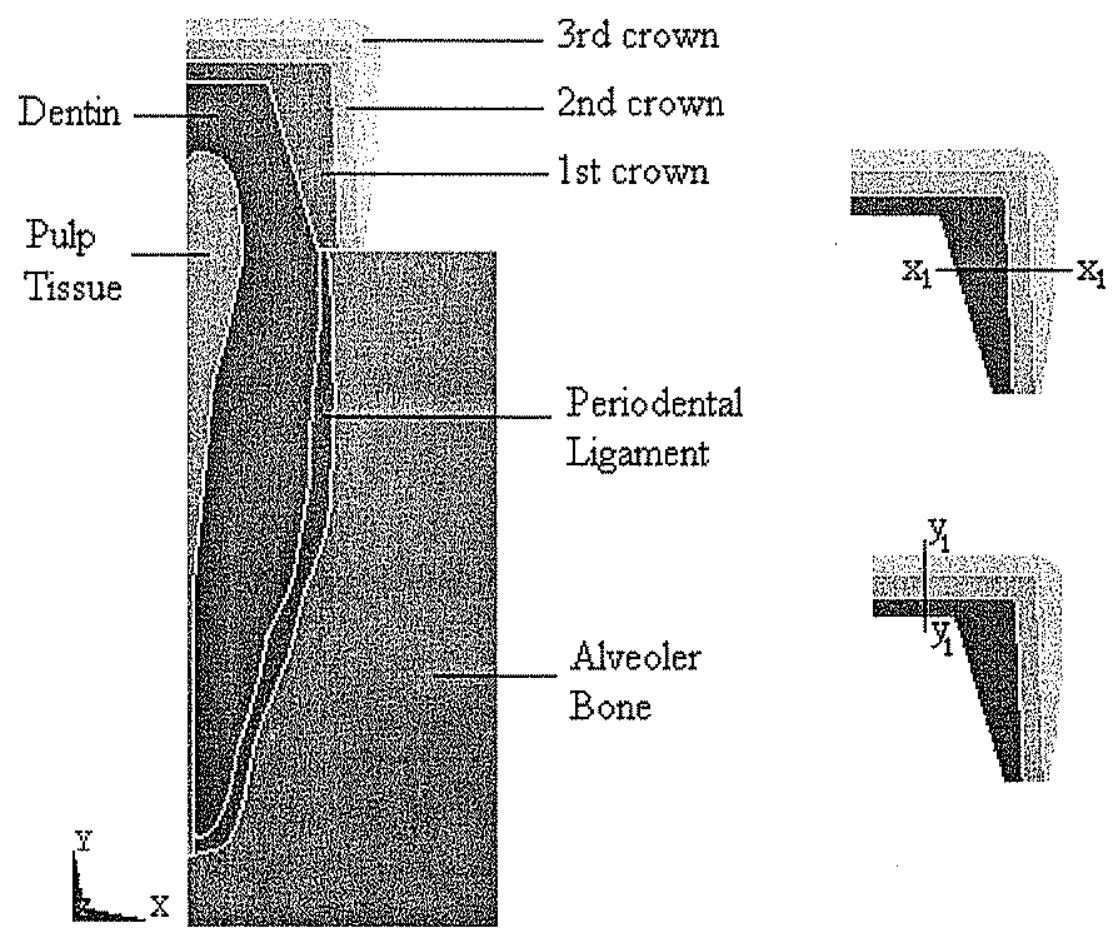

Figure 5 The structures of tooth and investigation of stress distribution along the $x-x$ and $y-y$ axis 
Two main crown materials, Metal Crowns and Metal-Ceramic Crowns, are used for the crown part of the tooth. There are 5 different types of Metal Crowns. These are Ti, Au, Au-Ag-Pd-Pt, Co-Cr-Mo and Ni-Cr-Mo. 7 different types of metals are used in the metal part of the MetalCeramic Crown. These are Au-Pt-Pd-Ag, Au-Pd-Ag, Au-Pd, Pd-Ag, Ag-Pd, Co-Cr-Mo and NiCr-Mo. Physical properties of crown materials are given in Table 3.

Table 3. Physical Properties of Crown Materials

\begin{tabular}{|c|c|c|c|}
\hline Crown Type & Modulus of Elasticity (MPa) & Poisson's ratio & Density (kg/mm3)x10E6 \\
\hline Au-Pt-Pd & 90500 & 0.33 & 18.30 \\
\hline $\mathrm{Au}-\mathrm{Pd}-\mathrm{Ag}$ & 93500 & 0.33 & 15.78 \\
\hline $\mathrm{Au}-\mathrm{Ag}-\mathrm{Pd}$ & 87900 & 0.33 & 16.89 \\
\hline $\mathrm{Au}-\mathrm{Pd}$ & 97200 & 0.33 & 15.70 \\
\hline $\mathrm{Pd}-\mathrm{Ag}$ & 106000 & 0.33 & 10.80 \\
\hline $\mathrm{Ag}-\mathrm{Pd}$ & 86630 & 0.33 & 11.47 \\
\hline $\mathrm{Co}-\mathrm{Cr}$ & 206300 & 0.33 & 8.52 \\
\hline $\mathrm{Ni}-\mathrm{Cr}$ & 210500 & 0.33 & 8.66 \\
\hline $\mathrm{Ti}$ & 117000 & 0.33 & 4.51 \\
\hline $\mathrm{Au}$ & 81000 & 0.33 & 19.30 \\
\hline Porcelain & 63000 & 0.19 & 2.40 \\
\hline
\end{tabular}

\section{DISCUSSION}

In this section, thermal stresses arising from the temperature difference between the tooth temperature and the temperatures of the food and drinks taken to mouth will be examined. The hot and cold drinks in mouth cause a temperature gradient in tooth; this gradient results in thermal stresses because of the different physical properties of different materials in tooth. As mentioned before, the highest temperature of the food and drinks that acts on the tooth will be taken as $60^{\circ} \mathrm{C}$. In other words, the maximum ambient temperature that acts on the tooth or the initial temperature is $60^{\circ} \mathrm{C}$. It is assumed that these temperatures have reached to the mouth temperature $\left(36.5^{\circ} \mathrm{C}\right)$ in one second.

The temperature of the tooth is taken the same as the body temperature which is $36.5^{\circ} \mathrm{C}$. Taking into consideration all these facts, the thermal stress distribution occurring in the tooth and the crown will be investigated for two different types of crown materials as Metal Crowns and Metal-Ceramic Crowns. The thermal stresses occurring in these two main crown types will be calculated separately along the $\mathrm{x}_{1}-\mathrm{x}_{1}$ and $\mathrm{y}_{1}-\mathrm{y}_{1}$ lines as shown before in Fig. 5. $\sigma_{\mathrm{x}}$ and $\sigma_{z}$ will be analysed along the $y_{1}-y_{1}$ line since their values are greater and $\sigma_{y}$ and $\sigma_{z}$ will be analysed along the $\mathrm{x}_{1}-\mathrm{x}_{1}$ line since they have greater values along this line. 


\subsection{Thermal Stress Distribution in Metal Crowns}

In this study, the thermal stresses occurring in the teeth for 5 different crown materials (Ti, $\mathrm{Au}$, $\mathrm{Au}-\mathrm{Ag}-\mathrm{Pd}-\mathrm{Pt}, \mathrm{Co}-\mathrm{Cr}-\mathrm{Mo}$, Ni-Cr-Mo), keeping the total crown part of the tooth from the same material has been examined. When the thermal stresses occurring in the crown part of the tooth in full metal crowns have been examined, it was seen that $\mathrm{Ti}, \mathrm{Co}-\mathrm{Cr}-\mathrm{Mo}, \mathrm{Ni}-\mathrm{Cr}-\mathrm{Mo}$ crowns have exhibited a similar distribution (Fig. 6 and Fig. 7). The reason for this is that the thermal characteristics of these crowns are similar to each other. Since the thermal characteristics of $\mathrm{Au}$ and $\mathrm{Au}-\mathrm{Ag}-\mathrm{Pd}-\mathrm{Pt}$ are close to each other, they also show a similar distribution.

In the examination of the figures, it is seen that compressive stresses are formed at the top part of $\mathrm{Ti}, \mathrm{Co}-\mathrm{Cr}-\mathrm{Mo}$, Ni-Cr-Mo crowns, while tension stresses are formed at the bottom part of these crowns (Fig. 6 and Fig. 7). The top part of the crown will tend to expand due to the high temperature acting on the crown surfaces. The bottom parts, on the other hand, will not expand as much as the top part since they do not have the same temperature. Therefore, compressive stresses will form at the top part of these crowns while tension stresses will form at the inner parts.

The highest stresses will form in $\mathrm{Ti}$, Co-Cr-Mo, Ni-Cr-Mo crowns, respectively (Fig. 6 and Fig. 7). Since the thermal expansion and conduction coefficients of $\mathrm{Au}$ and Au-Ag-Pd-Pt are higher than the others, they show a somewhat different distribution. Dentine will not expand as rapid as these crowns, since the temperature of the dentine under the crowns is $36.5^{\circ} \mathrm{C}$. For this reason dentine will exert compressive stresses to $\mathrm{Au}$ and $\mathrm{Au}-\mathrm{Ag}-\mathrm{Pd}-\mathrm{Pt}$ crowns. The crown part will exert a tension stress to the dentine since it will tend to expand.

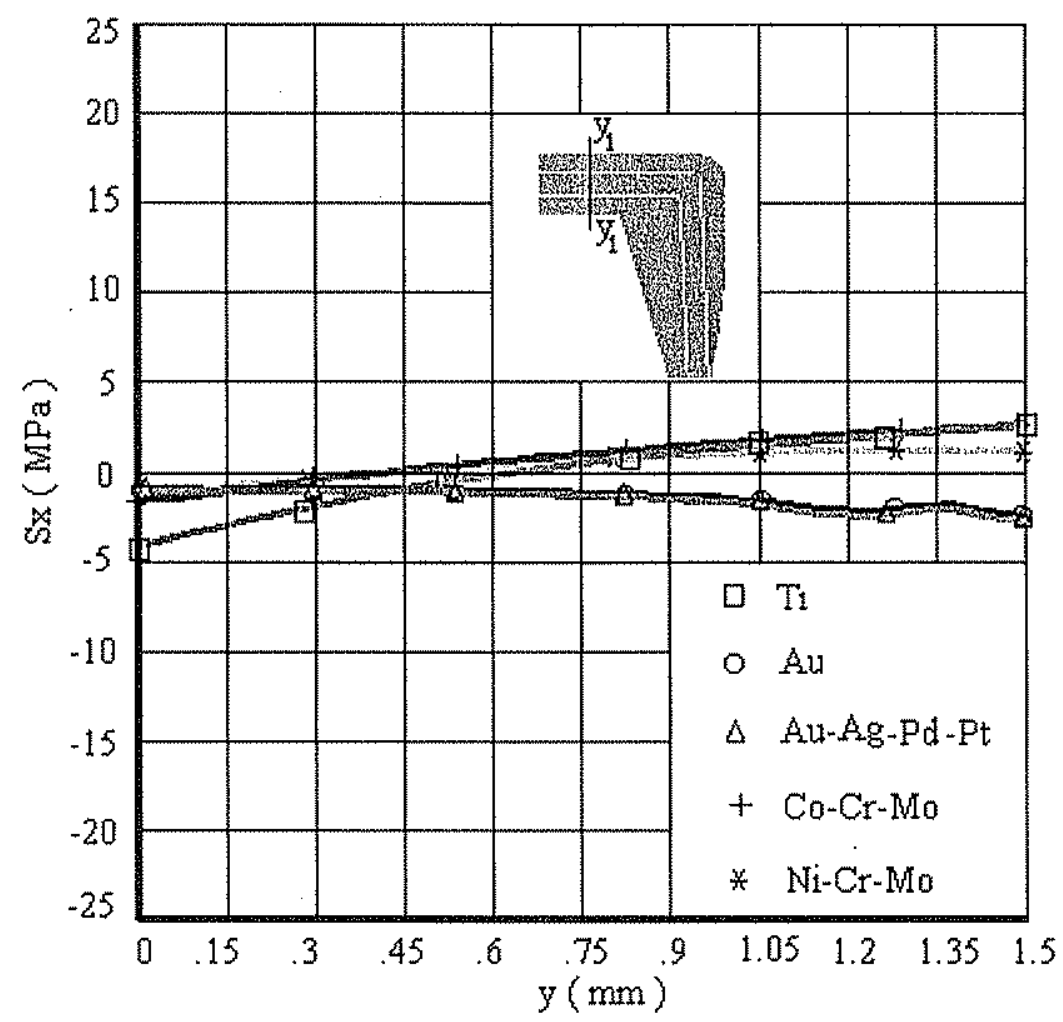

Figure 6. Distribution of $\sigma_{x}$ in the crown part of the tooth along the $y_{1-} y_{1}$ line. 


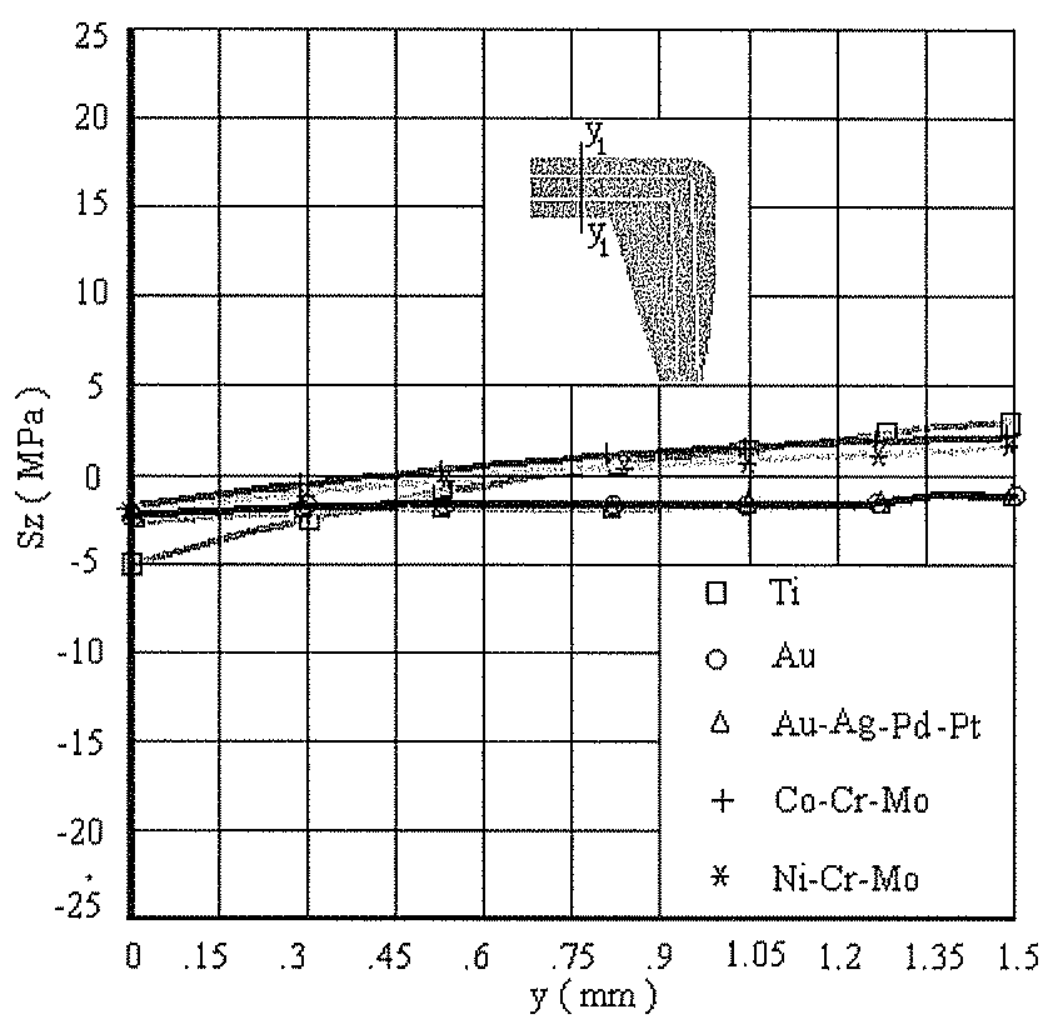

Figure 7. Distribution of $\sigma_{z}$ in the crown part of the tooth along the $y_{1-} y_{1}$ line.

Thermal stresses occurring along the $\mathrm{x}_{1} \mathrm{x}_{1}$ line have found to be dissimilar to those occurring along the $y_{1} y_{1}$ line due to the difference in thickness (Fig. 8 and Fig. 9).

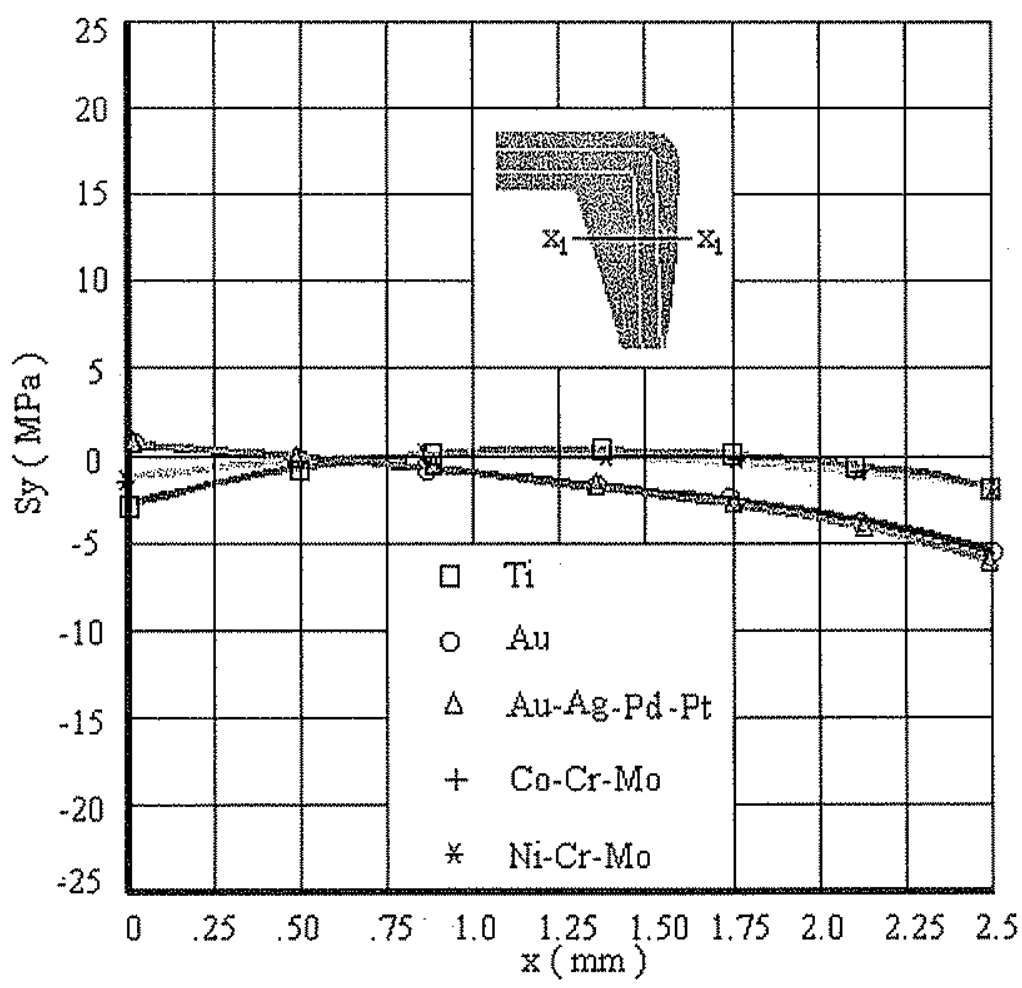

Figure 8. Distribution of $\sigma_{y}$ in the crown part of the tooth along the $\mathrm{x}_{1}-\mathrm{x}_{1}$ line. 


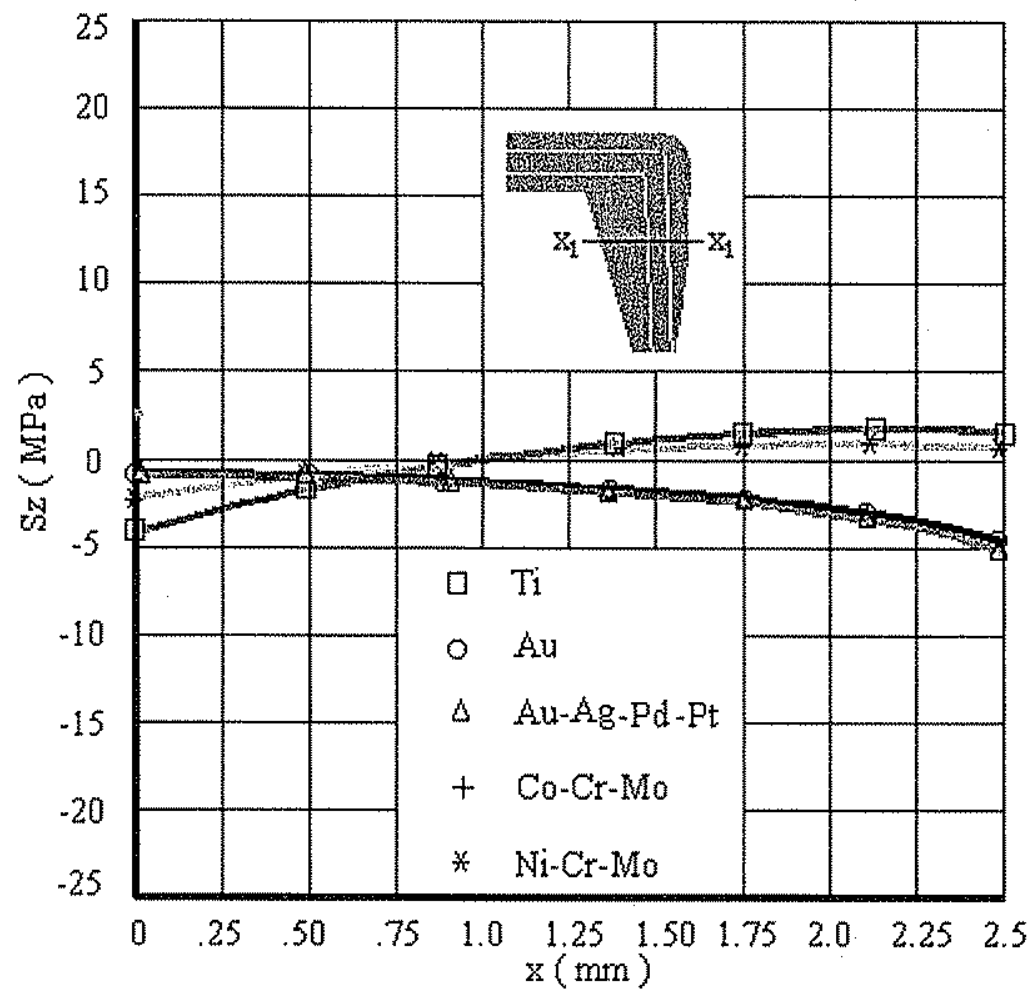

Figure 9. Distribution of $\sigma_{z}$ in the crown part of the tooth along the $x_{1}-x_{1}$ line.

\subsection{Thermal Stress Distribution in Metal-Ceramic Crowns}

In this study, the stress distribution of metal reinforced ceramic crowns named as MetalCeramic Crowns are investigated (Figure 10). 7 different types of metals are used in the metal part of the crown. These are Au-Pt-Pd-Ag, Au-Pd-Ag, Au-Pd, Pd-Ag, Ag-Pd, Co-Cr-Mo and $\mathrm{Ni}-\mathrm{Cr}-\mathrm{Mo}$.

When Metal-Ceramic crowns are investigated along the $x_{1}-x_{1}$ and $y_{1}-y_{1}$ lines it is seen that the highest thermal stresses are seen in Ag-Pd crowns, while the lowest are seen $\mathrm{Co}-\mathrm{Cr}-\mathrm{Mo}$ crowns (Fig. 11-14). The second highest thermal stresses are seen in Au-Pt-pd-Ag crowns after Ag-Pd crowns (Fig. 11-14). In $0.5 \mathrm{~mm}$ thick porcelain crown tension stresses; while in the metal crown below the porcelain crown compressive stresses occur (Fig. 11-14). Porcelain expands more slowly since its thermal expansion coefficient and thermal conductivity are lower than the others. Metal Crowns, on the other hand, expand more quickly. Since the metal crown will tend to elongate the porcelain crown in this case, tension stresses will form in the metal crown. The porcelain crown, which will not expand as same as the metal crown, will tend to prevent the metal crown; thus, compressive stresses will form in the metal crown.

It is seen that, because of the difference in thickness, stresses formed along the $y_{1-} y_{1}$ line will be higher than those formed along the $x_{1} x_{1}$ line (Figure 134 and Figure 14). The highest values of the stresses are metal the inner parts of the porcelain. The values of $\sigma_{\mathrm{x}}$ are higher than $\sigma_{\mathrm{y}}$ and $\sigma_{z}$, and also the values of $\sigma_{\mathrm{z}}$ are higher than $\sigma_{\mathrm{y}}$ (Figure 13 and Figure 14).

When compared with Metal Crowns, it is seen that the stresses increase by 4-5 times in MetalCeramic crowns. 


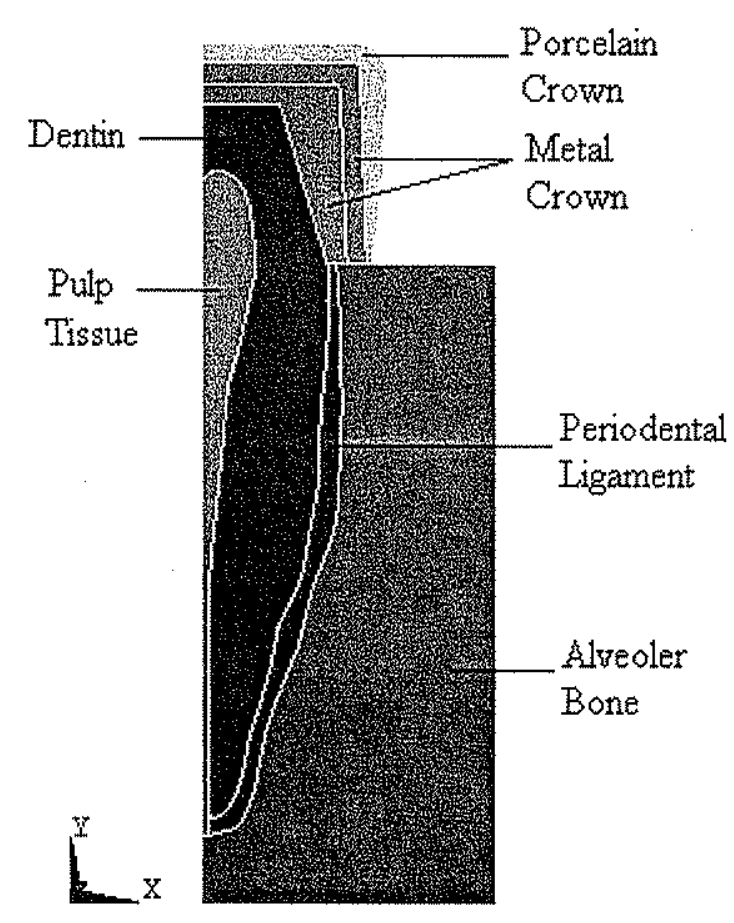

Figure 10. The structure of tooth and crown

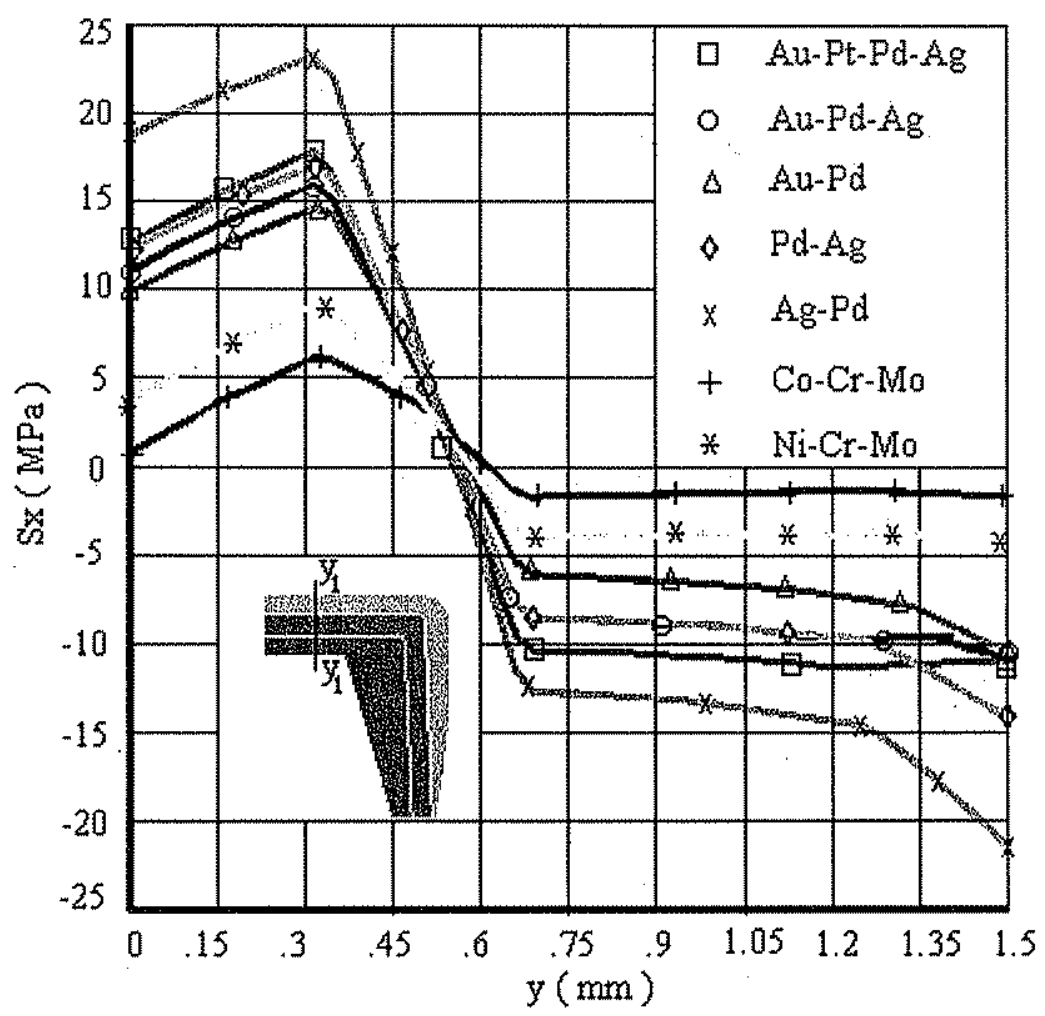

Figure $11 \sigma_{\mathrm{x}}$ distribution formed at the crown part of the tooth in metal-ceramic crowns along the $\mathrm{y}_{1} \mathrm{y}_{1}$ line 


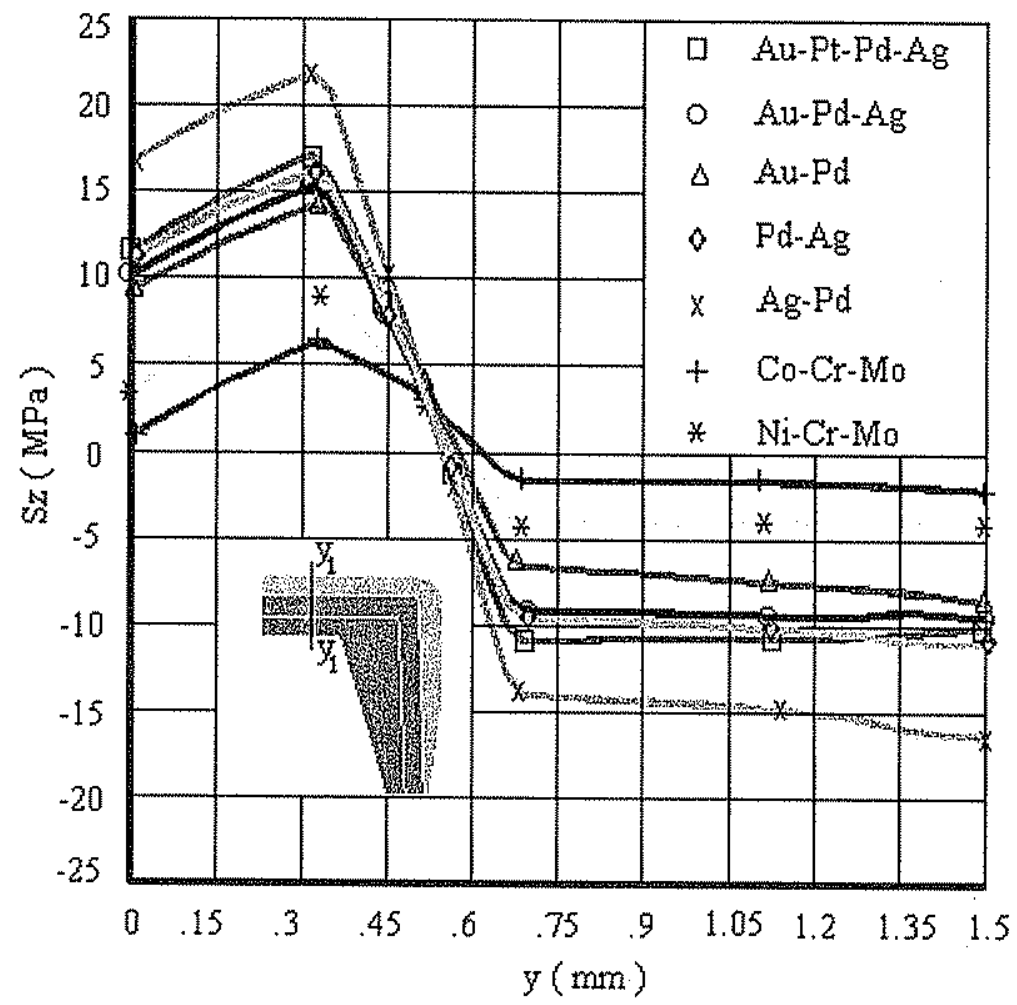

Figure 12. $\sigma_{z}$ formed at the crown part of the tooth in metal-ceramic crowns along the $y_{1}-y_{1}$ line

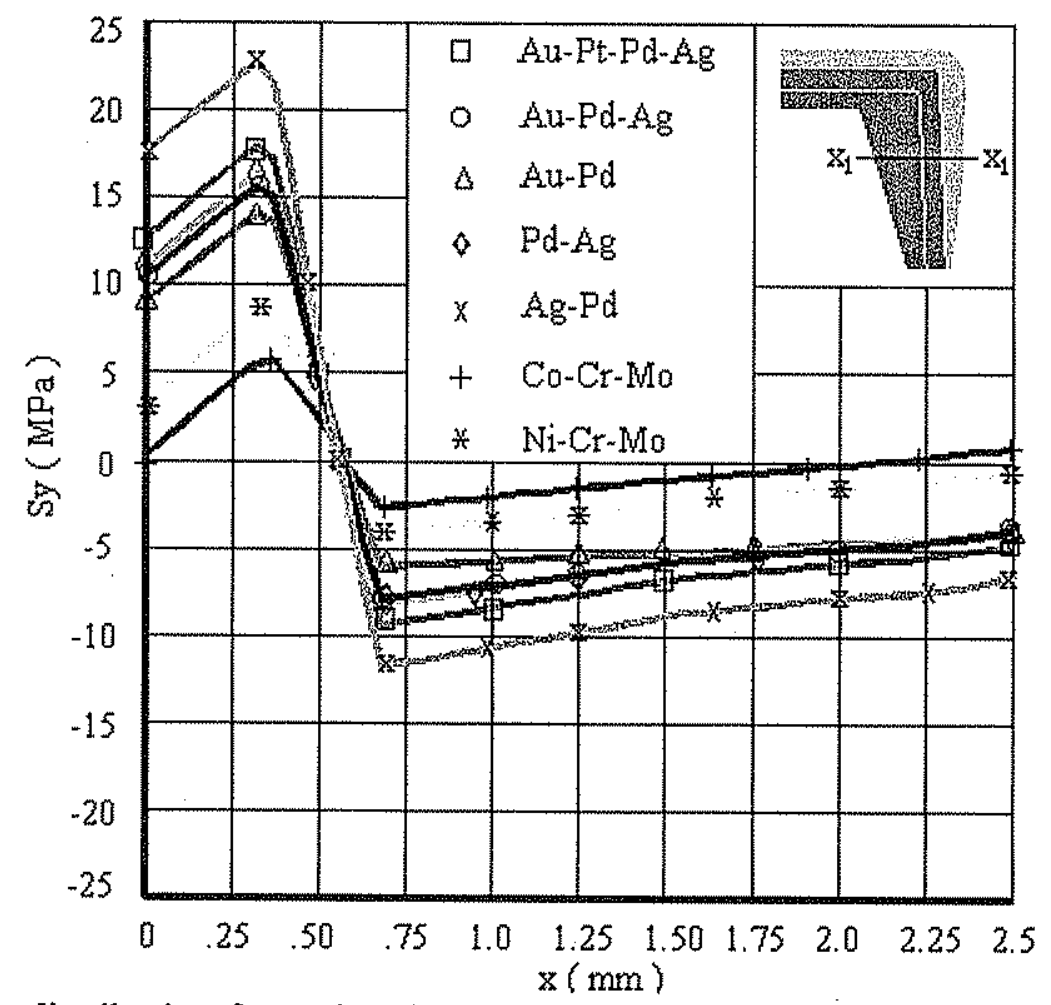

Figure 13. $\sigma_{y}$ distribution formed at the crown part of the tooth in metal-ceramic crowns along the $x_{1} \cdot x_{1}$ line 


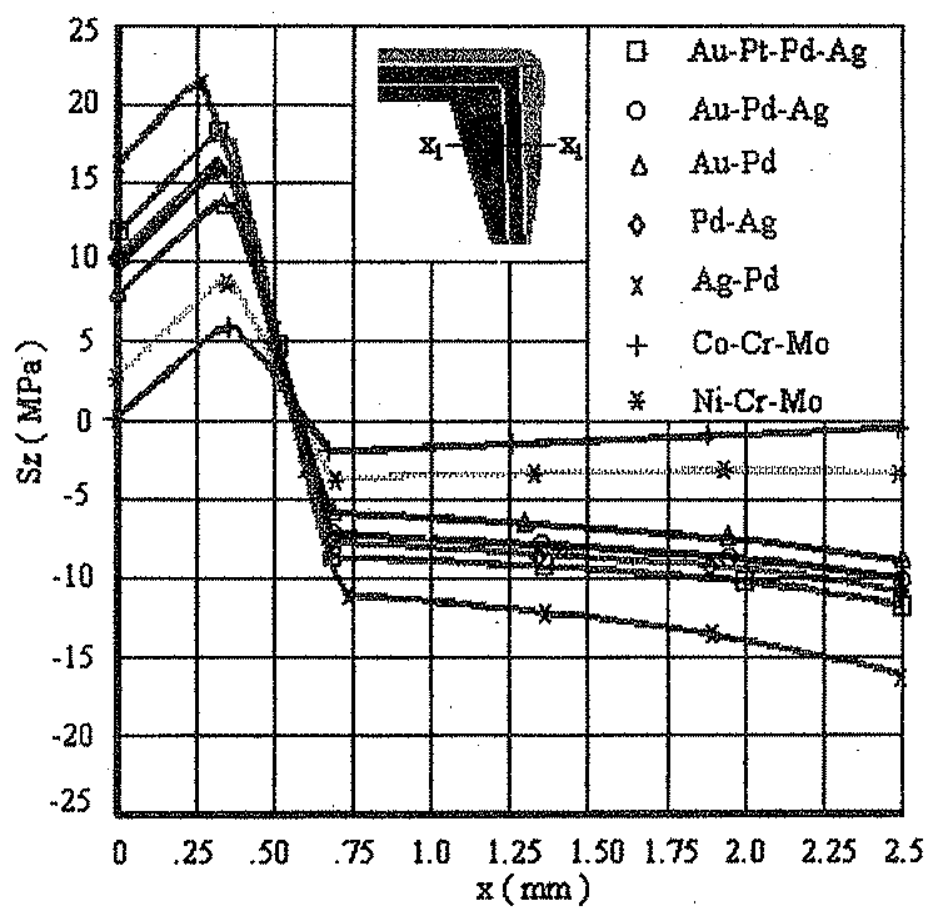

Figure 14. $\sigma_{z}$ distribution formed at the crown part of the tooth in metal-ceramic crowns along the $\mathrm{x}_{1} \mathrm{x}_{1}$ line

\section{CONCLUSIONS}

The following results have obtained in the thermal stress analysis of the maxillary right canine crowned with various crown materials:

1. Thermal stresses will form due to the difference between the tooth temperature and the temperatures of the hot food and drinks $\left(60^{\circ} \mathrm{C}\right)$ taken to the mouth.

2. When a food or beverage of $60^{\circ} \mathrm{C}$ is taken to mouth, it is seen that the thermal stresses occurring at the crown surface are lower for the metal crown and higher for the metalceramic crowns.

3. In metal crowns, the highest thermal stresses are in Ti crowns and the lowest are in Au crowns. In metal-ceramic crowns, the highest thermal stresses are in Ag-Pd crowns, while the lowest are in $\mathrm{Co}-\mathrm{Cr}-\mathrm{Mo}$ crowns. The thermal stresses occurring in metal - ceramic crowns are approximately five times greater than the thermal stresses in metal crowns. With respect to these results, metal-ceramic crowns are more prone in terms of heat compared to metal crowns.

4. The reason for obtaining the higher thermal stresses in metal-ceramic crowns is that porcelain is not as ductile as other metallic materials. Capillary cracks in the inner parts of the porcelain used in either metal-ceramic crowns produced during manufacture may due to high and continuously changing tension-compression stresses. Since the expansions and compressions occurring in the crown are higher than those in the dentine, crowns may deteriorate in time and may even become unusable.

5. With respect to the obtained results, when examined in terms of thermal aspects, the employment of metal crowns, which have very close thermal properties to dentine, may be preferred. If porcelain is preferred in the crown, than it is advised that metal-ceramic crowns that have close thermal properties to dentine must be preferred to the others. 


\section{REFERENCES}

1. Th. A. M. Spierings, M. C. R. B. Peters, F. Bosman and A. J. M. Plasschaert, Verification of Theoretical Modelling of Heat Transmission in Teeth by in vivo Experiments, J. Dent. Res. 66(8), 1336-1339, August, 1987.

2. M. Toparl, An investigation behavior of teeth by using various dental materials, Ph.D. Thesis, İmir, Dokuz Eylül University, Graduate School of Natural and Applied Sciences, 1996. 3. J.W. Mclean, M. I. Kedge and J. R. Hubbard, The bounded alumina crown, Aust. Dent. Journal, 21-262, 1976.

4. J.W. Mclean, The science and art of dental ceramics, Monographs 1-4, Quintessence Publishing Co., Chicago, 1979.

5. M.A. Major, Wheeler's atlas of tooth form, W.B. Saunders Company, Philadelphia, 1984. 
